\title{
Perbaikan Ruang Penunjang Kegiatan Mushola Di Kampung Lio, Cipayung, Jawa Barat
}

\author{
Dyah Nurwidyaningrum $^{1}$, Sarito $^{2}$, Eri Ester Khairas ${ }^{3}$ \\ 123 Jurusan Teknik Sipil, Politeknik Negeri Jakarta \\ Email: dyah.nurwidyaningrum@ sipil.pnj.ac.id
}

\begin{abstract}
Abstrak
Memperbaiki Mushola Al Khoiriyah di Kampung Lio adalah satu kegiatan sehingga keberadaan mushola tersebut lebih layak digunakan sebagai prasarana beribadah umat muslim di lingkungan RT.05/RW.09, Kelurahan Bojong Pondok Terong, Kecamatan Cipayung, Kota Depok. Terutama ketika musholla digunakan shalat tarawih pada bulan Ramadhan. Pada kegiatan Pengabdian pada Masyarakat kali ini untuk Prodi Konstruksi Gedung Politeknik Negeri Jakarta memperbaiki ruang penunjang mushola terutama perbaikan tempat wudhu dan toilet. Lingkup pekerjaan pada perbaikan dinding penahan tanah dan lantai tempat wudhu dan toilet. Dengan selesainya pekerjaan perbaikan tersebut, akan tersedia prasarana Mushola yang dapat meningkatkan ketakwaan serta keimanan kepada Tuhan Yang Maha Esa di lokasi yang dimaksud. Target khusus dari kegiatan ini adalah menyempurnakan fasilitas fisik mushola Al Khoiriyah di Kampung Lio, RT.05/RW.09, Kelurahan Bojong Pondok Terong, Kecamatan Cipayung, Kota Depok. Metode yang digunakan untuk mencapai tujuan di atas adalah Tim pengabdian masyarakat Program Studi Konstruksi Gedung, Jurusan Teknik Sipil, Politeknik Negeri Jakarta bekerjasama dengan warga secara bergotong royong melakukan perbaikan mushola tersebut. Kegiatan ini direncanakan selesai dalam waktu 2 bulan.
\end{abstract}

Keywords: musholla, toilet, tempat wudhu, dinding penahan tanah, lantai

\begin{abstract}
Repairing Al Khoiriyah Mosque in Lio Village is an activity so that the existence of the mosque is more suitable to be used as infrastructure for Muslim worship in RT.05 / RW.09, Bojong Village Pondok Terong, Cipayung District, Depok City. Especially when the mosque is used tarawih prayer in the month of Ramadan. In this Community Service activity the Building Construction Study Program of Politeknik Negeri for repairing supporting room of the mosque, especially the repair of ablution places and toilets. The scope of work is on repairing retaining walls and floors for ablutions and toilets. With the completion of the repair work, the mosque's infrastructure will be available that can increase piety and faith in God Almighty at the location in question. The specific target of this activity is to improve the physical facilities of Al Khoiriyah mosque in Lio Village, RT.05 / RW.09, Bojong Village, Pondok Terong, Cipayung District, Depok City. The method used to achieve the above goal is the Community Service Study Team of the Building Construction Study Program, Civil Engineering Department, Politeknik Negeri Jakarta in collaboration with residents working together to repair the mosque. This activity is planned to be completed within 2 months.
\end{abstract}

Keywords: musholla, toilet, ablution place, retaining wall, floor 


\section{Pendahuluan}

Kampung Lio RT 05/09, Kelurahan Bojong Pondok Terong, Kecamatan Cipayung, Kota Depok, Jawa Barat adalah salah satu wilayah yang terletak disebelah Selatan Kota Depok. Masyarakat dengan tingkat pendidikan yang lulus SD (sekolah dasar) mencapai 50\%, SMP (sekolah menengah pertama) sebesar 30\%, dan SMA (sekolah menengah atas) sebesar $10 \%$. Sebagian besar penduduk di Kampung Lio bekerja sebagai wirausaha, peternak dan petani. Disamping itu ada juga yang berprofesi sebagai pekerja konstruksi, dan sebagian kecil sebagai karyawan pabrik serta pekerja serabutan. Desa ini berjarak kurang lebih $12 \mathrm{~km}$ dari kampus Politeknik Negeri Jakarta. Secara geografis terletak di bagian selatan Kota Depok tepatnya di Jalan Bulak Timbul yang merupakan jalan lingkungan masuk dari Jalan Raya Cipayung Jaya.

Di Desa ini terindikasi adanya tingkat sosial ekonomi yang rendah, hal ini terlihat dari rendahnya tingkat pendidikan, pendapatan, standar hidup dan kesehatan, serta terbatasnya sarana dan dan prasarana. Kelurahan Bojong Pondok Terong, Kecamatan Cipayung khususnya kampung Pondok Lio RT. 05/09 berpenduduk lebih kurang $60 \mathrm{KK}$, dimana sekitar $50 \%$ dari jumlah KK tersebut hanya berpendidikan sekolah dasar saja. Dengan kondisi masyarakat yang berpenghasilan rendah seperti yang disebutkan di atas, maka sangatlah sulit untuk mengajak masyarakat berpartisipasi membangun desanya khususnya membangun fasilitas yang digunakan bersama, jika ditinjau dari segi pendanaan (keuangan). Hal ini tentunya sangat berbeda jika partisipasi mereka tidak dalam bentuk uang, yaitu berupa sumbangan tenaga (gotong royong). Dari hasil survei juga ditemukan bahwa kondisi kampung ini mempunyai prasarana ibadah berupa Mushola Al Khoiriyah terletak di jalan lingkungan Bulak Timbul namun kondisinya meprihatinkan sudah banyak bagian-bagian yang mengalami kerusakan serta belum sempurnanya bagian-bagian tertentu yang sebenarnya sangat dibutuhkan. Masyarakat setempat telah berupaya memperbaiki dan menyempurnakannya namun tingkat sosial ekonomi yang rendah sehingga perbaikan dan penyempurnaan mushola tersebut belum bisa direalisasikan.

Tempat wudhu Musholla Al Khoriyah yang diperbaiki, lantainya mempunyai ketinggian lebih rendah sekitar satu meter ke bawah dari lantai ruang sholat sehingga berpotensi licin. Untuk turun ke bawah dicapai dengan tangga yang curam dan lantai yang kurang bertekstur. Kim et al (2019) mengatakan merencanakan fasilitas sholat mempunyai tantangan dalam hazard agar tidak licin pada permukaan lantai yang basah, terutama di area tempat wudhu. Solusi yang ditawarkan adalah menguruk tanah sehingga lantai menjadi lebih tinggi dan mempunyai selisih turun yang kecil $<10 \mathrm{~cm}$ dari ruang sholat. Namun hal ini menyebabkan kurang kuatnya bagian dinding yang mengalami pengurukan sehingga diperlukan perkuatan pada dinding tersebut. Oleh karena kegiatan berwudhu adalah kegiatan yang menggunakan air, kekuatan lantai dan dinding perlu direncanakan agar pengaliran air tidak menyebabkan lantai dan dinding rusak. Sebagaimana Anwar et al (2015) mengungkapkan salah satu permasalahan tempat wudhu adalah pengairan limpahan air yang dapat mempengaruhi struktur lantai.

Tujuan dari kegiatan pengabdian masyarakat ini adalah untuk meningkatkan kelayakan prasarana tempat ibadah dan m emberikan penguatan/kemandirian kepada warga RT 05/09 Kampung Lio, Kelurahan Bojong Pondok Terong, Kecamatan Cipayung, perihal teknik pelaksanaan yang benar bagian dari pekerjaan bangunan Gedung. Hadiyana et al (2017) memperbaiki ruang penunjang masjid dapat meningkatkan kemauan beribadah masyarakat.

\section{Metode}

Budiono et al (2017) tentang desain toilet dan tempat wudhu masjid mengatakan konsep desain musholla harus memenuhi 4 (empat) syarat, yaitu: (1) terbebas dari najis, (2) menutupi aurat, (3) tidak menghadap atau membelakangi kiblat, dan (4) terhindar dari percikan air urine. Dengan konsep ini akan menjawab permasalahan tempat wudhu eksisting. Pendapat ini didukung oleh Hamid et al (2016) bahwa tempat wudhu sebagai kegiatan yang menjadi persyaratan untuk beribadah memiliki prosedur yang berkaitan dengan air dan mudah terpapar ketidak sucian dari toilet.

Bangunan sejak selesai konstruksi mempunyai umur tertentu atau masa layanan tertentu yang sesuai dengan bertambahnya umur bangunan akan mengalami penurunan fungsi dari setiap bagian bangunan tersebut. Selama masa layan dapat terjadi berbagai kondisi/ kerusakan yang berdampak pada lifetime bangunan. Terlebih lagi kerusakan yang berat dapat membahayakan keselamatan pengguna bangunan, sehingga perlu adanya jaminan keselamatan selama umur bangunan. Laju kerusakan ini sebenarnya dapat ditekan dengan pemeliharaan yang baik. Suatu bangunan yang memiliki pemeliharaan dan perawatan yang sesuai prosedur, akan berdampak pada lifetime bangunan tersebut. Oleh karena itu pemeriksaan dan perbaikan bangunan secara berkala haruslah dilakukan, sehingga bangunan dapat berfungsi selama masa umur layanan dan mampu

Mitra Akademia, Vol 2. No. 22019 
memberikan jaminan keselamatan bagi penggunanya.

Dalam pelaksanaannya, Tim Pengabdian Kepada Masyarakat Prodi Konstruksi Gedung Jurusan Teknik Sipil PNJ terdiri dari Dosen dan Mahasiswa bukan sebagai pelaksana utama kegiatan, melainkan sebagai fasilitator dalam program pengabdian ini. Wujud keterlibatan Mitra sebagai berikut:

a. Warga bersama-sama tim pengabdian bergotong royong dalam melaksanakan perbaikan Mushola Al Khoiriah. Dalam proses ini Tim Pengabdian memberikan contoh cara pelaksanaan pekerjaan yang benar sehingga warga mendapatkan pengetahuan dan keterampilan yang dapat diaplikasikan pada pekerjaan sejenis pada waktu yang akan dating.

b. Warga menyediakan air dan listrik pada saat berlangsungnya kegiatan dan membantu tim menggerakkan masyarakat. Selain itu warga memfasilitasi kebutuhan administratif dan kemudahan dalam mendapatkan bahan bangunan di lokasi.
Diagram proses pengabdian masyarakat ini yang telah dipaparkan, sebagai berikut pada Gambar berikut.

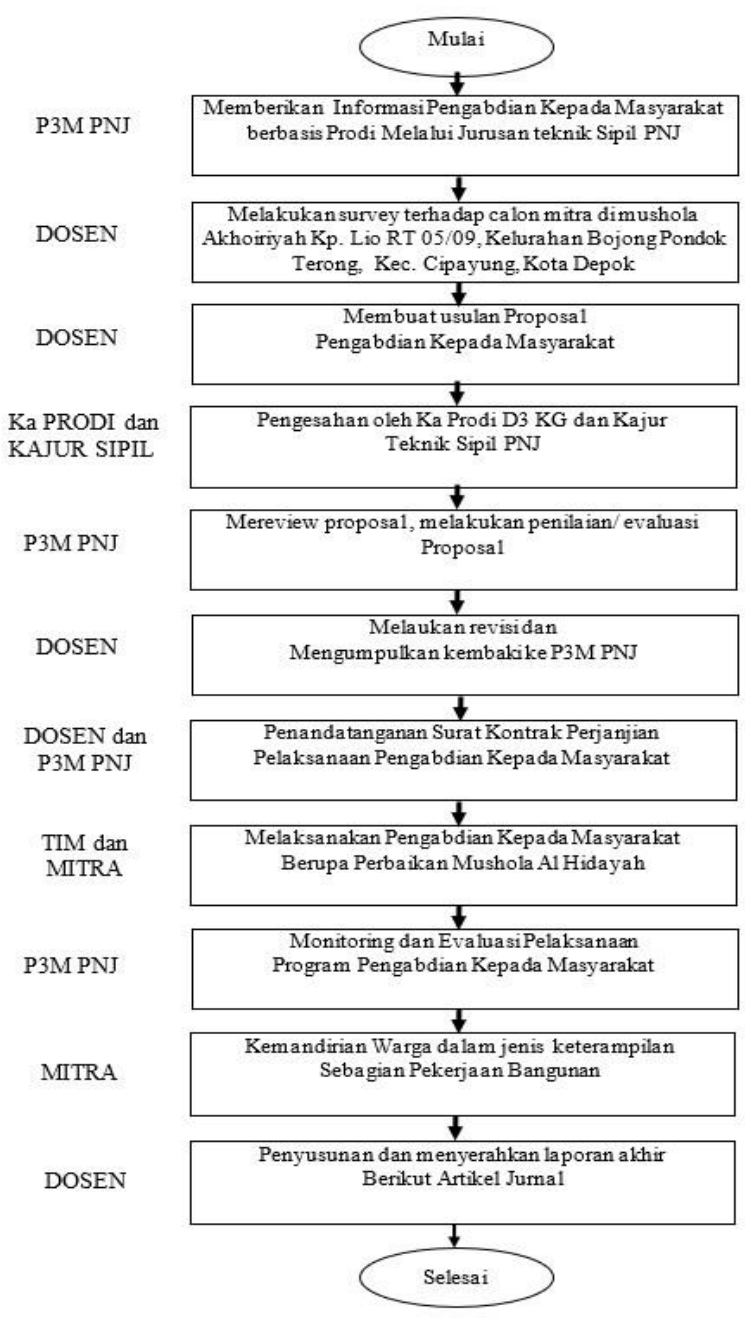

Gambar 1. Bagan Alir Tahapan Pengabdian Masyarakat

\section{Hasil dan Pembahasan}

Hasil pekerjaan pengabdian masyarakat Tim prodi Konstruksi Gedung Politeknik Negeri Jakarta menunjukkan bahwa pekerjaan telah dapat diselesaikan. Struktur lantai dan dinding telah diberi perkuatan dengan balok dan kolom tambahan. Balok dua rangkap atas dan bawah beserta kolom di empat tempat yang berjarak sama. Tulangan kolom dan balok dengan besi $12 \mathrm{~mm}$ yang terpasang dengan jarak $20 \mathrm{~cm}$ diperhitungkan mampu memberi kekuatan pada balok dan kolom penahan.

Mitra Akademia, Vol 2. No. 22019 
Bagian atas pondasi dari pondasi eksisting dinaikkan dengan pasangan bata hebel, sekaligus memperkuat hubungan pondasi, kolom dan balok tambahan. Dinding diberi kamprot untuk menyatukan kekuatan hubungan kolom, balok dan dinding dan siap untuk pengurugan dengan puing dan tanah. Tanah puing digunakan untuk menghemat biaya pengurugan. Setelah tanah diurug dianjutkan pemasangan keramik yang mempunyai tenktur yang tidak licin.

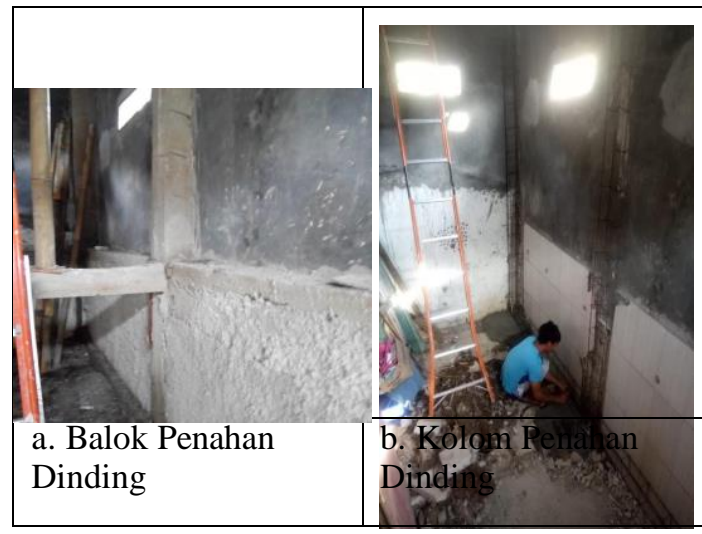

Gambar 2. Pekerjaan Struktur Balok dan Kolom Penahan

Konsep desain musholla teah memenuhi 4 (empat) syarat, yaitu terbebas dari najis, menutupi aurat, toilet tidak menghadap atau membelakangi kiblat, dan terhindar dari percikan air urine. Toilet dan tempat wudhu dibatasi oleh pintu dan dinding. Jarak keran air dipasang dengan jarak 1,2 m untuk menghindari percikan air antar orang yang sedang berwudhu. Arah pengaliran air buangan disesuaikan dengan struktur dinding yang terbentuk dan jarak orang ke keran air.

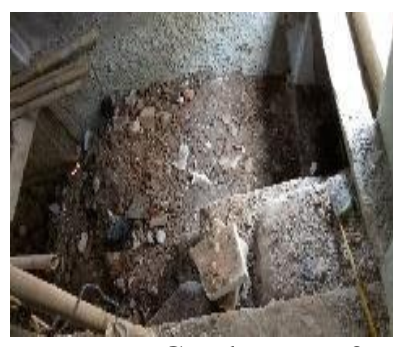

Gambar

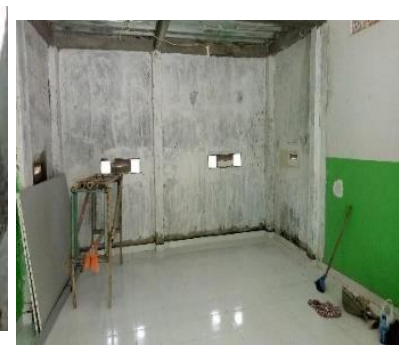

Pekerjaan Pengurugan dan Penyelesaian Lantai

Beberapa kendala dihadapi pada saat pelaksanaan adalah sebagai berikut:

1. Pada tahap persiapan adalah perubahan rencana letak tempat wudhu karena perbedaan ketinggian tanah yang tinggi sekitar 1 meter. Perubahan ini untuk mencapai perencanaan ruang yang lebih efisien sehingga area sholat menjadi lebih luas dan tempat wudhu tidak melewati area sholat. Akan tetapi kembali kepada perencanaan semula karena tidak mendapatkan ijin perubahan.

2. Saat pelaksanaan kegiatan mundur dari waktu yang ditetapkan karena ada prioritas untuk menyelesaikan atap terlebih dahulu. Selain itu tempat wudhu perlu diurug yang membutuhkan waktu pemesanan untuk mendatangkan tanah puing tersebut. Jadi waktu mundur satu minggu dari seharusnya.

3. Pekerjaan dapat diselesaikan tapi membutuhkan waktu dan keluasaan tempat wudhu yang terbatas menyebabkan jumlah tukang tidak dapat ditambah lagi.

Kendala pertama diatasi dengan menjadikan kesatuan perencanaan ruang penunjang terhadap ruang sholat. Tim membagi area tempat wudhu dan toilet yang diperbaiki untuk jama'ah wanita sedangkan tempat wudhu dan toilet yang telah dibangun masyarakat di luar untuk jama'ah lakilaki. Dengan demikian jema'ah wanita tetap tertutup aurat saat berwudhu. Kemunduran waktu direncanakan tidak mengganggu aktifitas kegiatan sholat dengan cara bergantian perbaikannya. Saat tempat wudhu di bagian belakang diperbaiki, jemaah tetap bisa berwudhu pada tempat Wudhu di samping.

\section{Kesimpulan}

Hasil pengabdian ini menunjukkan program perbaikan Musholla Al Khoiriyah Kampung Lio RT

05/09 Bojong Pondok Terong, Kecamatan Cipayung, Kota Depok, dilakukan dengan kerjasama yang melibatkan masyarakat. Peran aparat desa mengupayakan pemeliharaan tempat ibadah dan mendorong masyarakat berperilaku higienis dan mempertahankan kebersihan. Pelaksanaan pengabdian masyarakat ini mengajarkan ilmu pengetahuan selain membantu memperbaiki ruang penunjang ibadah.

\section{Saran}

Untuk memperlancar kegiatan ini, diperlukan partisipasi mitra, yaitu warga yang lebih luas bersama-sama tim pengabdian bergotong royong dalam melaksanakan perbaikan dan pemeliharaan Musholla. Kendala yang dihadapi pada saat pelaksanaan perbaikan Musholla ini yaitu mundurnya waktu penyelesaian pekerjaan dari 
jadwal yang ditentukan, dapat diatasi dengan pembagian pekerjaan antara tim dengan masyarakat lebih proporsional. https://www.researchgate.net/publication/289253959 _Standar_Perancangan_TEMPAT_WUDH U_dan_TATA_RUANG_MASJIDpdf.

\section{Daftar Pustaka}

Anwar R., Abidin S.Z., Hassan O. H. (2015). Function Means Analysis for Ablution Concept

Solution. The Turkish Online Journal of Educational Technology (TOJET). September. P. 224231.

Budiono, Anggraeni L. K. (2017). Desain Toilet dan Tempat Wudhu Masjid. Jurnal Desain Interior, Vol.2, No.1, Juni, eISSN 25492985. P.1-11.

Community Sanitation Governance (CSG). 2016. A Riview and Comparative Analysis if Indicative Service Costs for Different Sanitation Service Scales in Indonesia. Institute for Sustainable Futures. 1-25.

Hadiyana D., Puspita N. (2017). Pembangunan/Renovasi Tempat Wudhu Masjid Nurul Iman di

Komplek Kanwil Kehutanan Provinsi Sumatera Selatan, Palembang. Jurnal Abdimas Mandiri Vol. 1 N.1, November, eISSN: 2598-425X, p.14-18.

Hamid A.B.A., Wahab M.H.A., Alias A., Rahmat N. (2016) Ablution Design: The Concepts and Design Criteria. In: Abidin S., Legino R., Noor H., Vermol V., Anwar R., Kamaruzaman M. (eds) Proceedings of the 2nd International Colloquium of Art and Design Education Research (i-CADER 2015). Springer, Singapore.

Kim In-Ju, Omar, H.O. (2019). Safety Assessment of Ablution Floors in Mosques: Measurement of slip resistance performance and surface features. Advances in Science and Engineering Technology International Conferences (ASET). IEEE Xplore.

Standar Nasional Indonesia (SNI). 2002. Tata Cara Perencanaan Bangunan MCK Umum. SNI 03-2399-002. ICS 27.180. Badan Standardisasi Nasional.

Suparwoko W. (2016). Standar Perancangan Tempat Wudhu dan Tata Ruang Masjid. Universitas Islam Indonesia. Januari. DOI: $\quad$ 10.13140/RG.2.1.3976.2000. 